\title{
Development of Methodological Standards in CNS Pharmacoeconomic Research: Report of an ACNP Task Force
}

Pharmacoeconomics is a relatively new science that has become increasingly important in recent years. Pharmacoeconomics may be defined as the assessment of the costs of clinical outcomes associated with alternative drug treatments (Walley and Haycox 1997). Results of pharmacoeconomic studies are crucial to decisions about governmental approval for new drug indications, formulary decisions in large healthcare organizations, as well as national health-care systems and programs. However, many concerns have been raised about investigator independence and possible bias in the design, analysis, and reporting of pharmacoeconomic studies (Hillman et al. 1991; Kassirer and Angell 1994).

Unfortunately, many researchers and decision makers are not sufficiently familiar with principles of pharmacoeconomics, research design, and data analytic techniques, and, therefore, have difficulty in evaluating the veracity and implications of findings of pharmacoeconomic studies. This is particularly true in the area of psychopharmacology. Although several authors have reviewed pharmacoeconomic methodology in the area of psychopharmacology (Hargreaves et al. 1998; Revicki 1999; Revicki and Luce 1995), impact on the general research community has been modest. To address this issue, the American College of Neuropsychopharmacology (ACNP) established a Task Force to Develop Methodologic Standards for Pharmacoeconomic Research Regarding CNS Compounds. The Task Force comprises members of the ACNP, non-ACNP scientists, and representatives of the pharmaceutical industry with expertise in pharmacoeconomic research. All non-ACNP members had publications in either CNS or related health economics outcomes research. The Task Force developed a set of criteria to assist in the evaluation of the quality of the methods and reporting of a pharmacoeconomic study involving CNS products.
This editorial briefly summarizes the deliberations of the Task Force and presents these criteria. We refer the reader for further information to the full text of the ACNP Task Force Report at HYPERLINK http:/ / www. acnp.org/citations/Npp03140192 http://www.acnp.org/ citations/Npp03140192.

\section{DESCRIPTION OF THE CRITERIA}

Task Force members compiled a pool of over 200 rating criteria and standards from existing pharmacoeconomic research literature, guidelines, and standards. These involved general research concerns, such as whether the hypothesis was clearly stated and whether the methods used tested the hypothesis adequately. Also included were specific pharmacoeconomic concerns, such as whether direct, indirect, and intangible costs were identified and whether the clinical outcomes were defined and linked to pharmacoeconomic outcomes. Direct costs refer to expenses incurred, including the cost of diagnosis, treatment, prevention, rehabilitation, and long-term care. Indirect costs refer to reduced earnings from decreased productivity and absenteeism. Intangible costs refer to a patient's impaired quality of life, including pain, suffering, and stress (Greenberg et al. 1993; Russell et al. 1998).

Redundant criteria were either eliminated or consolidated into 33 individual criteria, which were grouped into seven categories (Scope of Study; Study Objectives; Sample; Methods; Definitions; Results and Discussion; and Conclusions). Each criterion was evaluated on an 8-point Likert scale, ranging from 1 (unreasonable/no support) to 8 (reasonable/full support). Three articles (Boyer et al. 1998; Rosenheck et al. 1997; Sclar et al. 1995), varying in study type (cost identification and cost effective- 
ness) and disease entity under investigation (depression and schizophrenia) were selected to test the feasibility of the draft criteria. The results of the feasibility study were used to come up with 29 revised criteria (see Table 1), which were regrouped into five domains (Study Scope and Objectives; Pharmacoeconomic Definitions and Assumptions; Design; Results; Discussion and Conclusions). This set of 29 criteria was re-evaluated on a 6-point Likert scale using three new psychopharmacologic articles. These studies were chosen, because they represent modeling, cost-effectiveness, and cost-identification methodologies in schizophrenia or depression pharmacotherapy and pharmacoeconomic research (Ginsberg et al. 1998; Revicki et al. 1997; Simon et al. 1996).

\section{EVALUATION OF THE CRITERIA}

The criterion ratings of the Task Force members on the three articles provided assistance in evaluating the usefulness of the publications. Ratings of an article from each individual criterion were summed within each of the five domains. Then, an over-all summary score was calculated for each article by averaging the means of each of the five domain scores.

Reports with an over-all score of equal to or greater than 5 are likely of high quality. Those in the range of 3.0 to 4.9 are likely acceptable. Those with a score of less than 3.0 are likely unacceptable and should be viewed with skepticism.

\section{COMMENT}

The ACNP Task Force has developed and tested a set of 29 criteria that can assist researchers, clinicians, and policy makers in the assessment of the quality of published reports of pharmacoeconomic studies in the psychopharmacologic area. These criteria should be considered guides in assessing quality, and should not be considered a true scale, which would require a significantly larger sample of independent ratings of studies.

Guideposts for reading and evaluating reports have successfully improved the comprehensiveness of scientific studies in other areas. An example is when methodologic variables for studies in depression were for-

Table 1. Criteria for Evaluation of Pharmacoeconomic Research in CNS

I. Study scope and objectives

1. credible evidence that intervention works for conditions under study, well described

2. hypothesis clearly stated

3. economic perspective of study stated and well described

4. significance and rationale adequately addressed

II. Pharmacoeconomic definitions and assumptions

5. types and sources of costs clearly stated and reasonable

6. economic and clinical assumptions explicitly stated, defined, researchable, and reasonable

7. direct, indirect, and intangible costs relevant to study are identified and well described

8. clinical outcomes defined and reasonable and linked to pharmacoeconomic outcomes

III. Design

9. sampling definitions clear and appropriate, with inclusion/exclusion criteria and source of sample described

10. methods and study design appropriate for hypothesis being tested

11. methods clearly and fully described so that study can be replicated

12. duration of study is appropriate endpoints and conclusion

13. data analysis techniques appropriate for hypothesis and study design

14. data sources clearly and fully defined

15. random assignment, or if randomization not possible, nonrandomization adequately addressed

16. treatment comparator(s) appropriate

17. discounting, constant monetary value, or other method to control for inflation

IV. Results

18. important/key sample characteristics well described, including those of excluded subjects

19. appropriate sensitivity analyses perform/addressed

20. relevant data presented clearly and comprehensively

21. statistical reporting appropriate and comprehensive (e.g., variability, $p$-value)

V. Discussion and conclusions

22. use of post hoc analyses addressed and discussed

23. major conclusions supported by the results and methodology of study

24. economic impact relevant and well described

25. baseline or other differences among treatment groups adequately addressed, statistically or otherwise

26. clinical and economic significance adequately described

27. limitations of the study, based on assumptions, study type, modeling decisions, secular trends, potential confounds, regression to the mean, or other factors adequately addressed.

28. generalizability of findings addressed

29. financial relationships are disclosed 
mulated at the International Dahlem Conference published by Angst (1983) and then adopted and republished in several other journals (Kupfer and Rush 1983a; 1983b; 1983c).

The present set of criteria is consistent with and extends previously proposed guidelines for economic evaluation of pharmacological products and is developed to evaluate efficiently the quality and credibility of research reports. Because pharmacoeconomics is a young and emerging field, and this set of criteria has not been evaluated using large samples of clinical and health policy researchers, continued development and refinement is warranted, and encouraged by the ACNP Task Force.

Robert M.A. Hirschfeld, M.D. Department of Psychiatry \& Behavioral Sciences The University of Texas Medical Branch 1.302 Rebecca Sealy Hospital 301 University Boulevard Galveston, TX 77555-0188. Tel.: (409) 747-9791; Fax: (409) 747-8300.

E-mail:rohirsch@utmb.edu

\section{ACNP Task Force:}

R.M.A. Hirschfeld, Department of Psychiatry \& Behavioral Sciences, University of Texas Medical Branch, Galveston, TX,USA; J. Russell, Department of Psychiatry \& Behavioral Sciences, University of Texas Medical Branch, Galveston, Texas, USA; M. Buatti, WyethAyerst Laboratories, Philadelphia, PA, USA; T. Croghan, Health Services and Policy Research Department, Eli Lilly and Company; D.L. Dunner, Department of Psychiatry and Behavioral Sciences, University of Washington, Seattle, WA, USA; G. Fulop, Medical Policy and Programs, Merck-Medco Managed Care, L.L.C.; J. Greden, Department of Psychiatry, University of Michigan Medical Center; A.N. Grudzinski, Pfizer, Inc., New York, NY, USA; G. Hess, Care Sciences, Inc., Philadelphia, PA, USA; T. Hylan, Pfizer, Inc, New York, NY, USA; M.B. Keller, Department of Psychiatry and Human Behavior, Butler Hospital, Brown University, Providence, RI, USA; J.A. Lieberman, Department of Psychiatry, University of North Carolina School of Medicine; R.E. Meyer, Best Practice, L.L.C.; R. Miceli,Pfizer, Inc., New York, NY, USA; D. Revicki, MEDTAP International, Bethesda, MD, USA; J.F. Rosenbaum, Department of Psychiatry, Massachusetts General Hospital, Harvard Medical School, Boston, MA, USA; A.F. Schatzberg, Department of Psychiatry and Behavioral Sciences, Stanford University School of Medicine, Stanford, CA, USA; J. van Loon, Quathos, Advanced Health Outcomes Solutions, The Netherlands.

\section{REFERENCES}

Angst J (1983): The origins of depression. Current concepts and approaches. Report of the Dahlem Workshop on the Origins of Depression. Berlin, October 31-November 5, 1982. Berlin: Springer, pp 438-440

Boyer P, Danion JM, Bisserbe JC, et al. (1998): Clinical and economic comparison of sertraline and fluoxetine in the treatment of depression. Pharmacoeconomics 1:158-169

Ginsberg G, Shani S, Lev B (1998):Cost-benefit analysis of risperidone and clozapine in the treatment of schizophrenia in Israel. Pharmacoeconomics 2:231-241

Greenberg PE, Stiglin LE, Finkelstein SN, Berndt ER (1993): The economic burden of depression in 1990. J Clin Psychiat 54:405-418

Hargreaves W, Shumway M, Hu TW, Cuffel B (1998): Cost Outcome Methods for Mental Health. San Diego, Academic Press

Hillman AL, Eisenberg JM, Pauly MV, Bloom BS, Glick H, Kinosian B, Schwartz JS (1991): Sounding board. Avoiding bias in the conduct and reporting of cost-effectiveness research sponsored by pharmaceutical companies. N Engl J Med 324(19):1362-1365

Kassirer JP, Angell M (1994): The journal's policy on costeffectiveness analyses. N Engl J Med 331:669-670

Kupfer DJ, Rush AJ (1983a): Recommendations for scientific reports on depression. Am J Psychiat 140(10):1327-1328

Kupfer DJ, Rush AJ (1983b): Recommendations for depression publications [letter]. Arch Gen Psychiat 40(9):1031

Kupfer DJ, Rush AJ (1983c): Recommendations for depression publications [letter]. Psychiat Res 8(3):238-41

Revicki DA (1999): Pharmacoeconomic studies of atypical antipsychotic drugs for the treatment of schizophrenia. Schizophr Res 35 Suppl:S101-109

Revicki DA, Brown RE, Keller MB, et al. (1997): Cost-effectiveness of newer antidepressants compared with tricyclic antidepressants in managed care settings. J Clin Psychiat 58:47-58

Revicki DA, Luce BR (1995): Methods of pharmacoeconomic evaluation of new medical treatments in psychiatry. Psychopharmacol Bull 31(1):57-65

Rosenheck R, Cramer J, Xu W, et al. (1997): A comparison of clozapine and haloperidol in hospitalized patients with refractory schizophrenia. N Engl J Med 337:809-815

Russell JM, Patterson J, Baker AM (1998): Depression in the workplace: Epidemiology, economics, and effects of treatment. Health Outcomes 4:135-142

Sclar DA, Robison LM, Skaer TL, et al. (1995): Antidepressant pharmacotherapy: Economic evaluation of fluoxetine, paroxetine, and sertraline in a health maintenance organization. J Int Med Res 23:395-412

Simon GE, VanKorff M, Heiligenstein JH, et al.(1996): Initial antidepressant choice in primary care. JAMA 275:18971902

Walley T, Haycox A (1997): Pharmacoeconomics: Basic concepts and terminology. Br J Clin Pharmacol 43:343-348 